\title{
Finite Element Modeling of Strain Distribution through Sheet Thickness during Cold Rolling with Grooved Rolls
}

\author{
Pesin A. ${ }^{1, \text { a }}$, Pustovoytov D. ${ }^{1, \mathrm{~b}}$, Kolesnik A. ${ }^{1, \mathrm{c}}$, Pesin I. ${ }^{1, \mathrm{~d}}$ \\ ${ }^{1}$ Nosov Magnitogorsk State Technical University, \\ 38, Lenin prospect, Magnitogorsk, 455000, Russia
}

\begin{abstract}
Plastic strain control of aluminum alloys are of importance for improvement of sheet microstructure and properties. The paper presents a numerical analysis of the strain distribution through pure Al sheet thickness during cold rolling with flat and grooved rolls. FEM simulations were carried out with using software DEFORM 3D. For verification of the numeric modeling results, the experimental analysis was carried out. The influence of the roll shape on strain distribution through $\mathrm{Al}$ sheet thickness was studied. It was shown that the strain effective increases from 0.9 to 1.5 during cold rolling with grooved rolls, when depth of indentation of grooved rolls in sheet increases from 0.25 to $0.50 \mathrm{~mm}$. FE model can be used to optimize the cold rolling process to improve microstructure and mechanical properties of aluminum sheets.
\end{abstract}

\section{Introduction}

Aluminum and its alloys have very attractive features such as lightweight and high specific strength and they are widely used as structural materials in aerospace, automotive and other industries [1]. Plastic strain control of aluminum alloys are of importance for improvement of sheet microstructure and properties [2-5]. Many processes for controlling plastic strain and microstructure have been proposed and their effectiveness has been discussed. Periodical straining rolling (PSR) process that employs the pinion-like or worm-gear-like grooved roll to introduce periodically localized plastic strain in rolled sheet have proposed in [6]. This process was developed to control strain distribution to generate microstructure and texture in rolled sheet. It was experimentally proved [6] that the PSR process is able to weaken the basal texture and to improve the microstructure evolution of magnesium sheets. Investigation of the cold rolling of copper sheets having periodical artificial grooves running either in the rolling direction (longitudinal grooves) or in the width direction (transverse grooves) was reported in [7]. Triangular grooves were machined periodically on one surface of the sheet with a shaper. Initial contact ratio was varied by changing pitch between two adjacent grooves. With increasing reduction in thickness by the rolling, depth as well as width of grooves decreases, meanwhile contact ratio between the sheet and the roll increases. It was also found that grooves running in the transverse direction were more flattened than those in the rolling direction. Effects of cold rolling with grooved rolls and following flattening on both the cold rolling texture and the primary recrystallization texture of steel sheets were studied in [8]. In comparison with the cold rolling texture of the specimen conventionally flat rolled, the texture of the specimens subjected to the cold rolling with grooved rolls was composed of lower and higher components.

FE analysis of the roll-to-roll forming of micro cavities was carried out in [9] research paper. Based on the analysis results, the draft angle, pitch, and forming temperature were designed to get desired cavity shape without crack. FE simulations of the cold rolling process were performed in [10] using an optimized FE mesh and an extrapolation of the stress-strain law. Complex profile with five grooves was formed by in-feed method using two rolls. The calculated distribution of yield stress in the superficial layers of the workpiece was in good correspondence with measurements of micro-hardness. FE analysis of the sheet rolling with flat and grooved rolls was carried out in [11]. The process of grooved rolling was implemented in rolls whose surface had a shape of multiple-thread helicoids with round tips. It was demonstrated that sheet metal rolled in grooved rolls had higher mechanical properties (yield stress, ultimate strain) than sheet metal rolled in flat rolls only.

The goal of this research is to determine and to compare the strain distribution through Al sheet thickness during cold rolling with flat and grooved rolls.

\section{Research method}


The processes of cold rolling with flat and grooved rolls (Fig. 1-2) were simulated using commercial software DEFORM 3D, based on finite element method (FEM). Pure aluminum DIN-A1-99.7 was selected as rolled material. In the course of simulation, the following assumptions were made: 1) deformed medium hardened rigid-plastic material; 2) work rolls absolutely rigid; 3) conditions of deformation isothermal. To approximate the geometric parameters of the sheet, brick mesh was used. A Coulomb friction model was used between rolls and sheet, which assumes that no relative motion occurs if the equivalent frictional stress is less than a critical value. The friction coefficient $\mu=0.3$ was calibrated by experimental tests and FEM simulations. The initial data: 1) sheet thickness $\mathrm{H}_{0}=4.0 \mathrm{~mm}$, sheet width $\mathrm{B}_{0}=40 \mathrm{~mm} ; 2$ ) work roll radius $\mathrm{R}=100 \mathrm{~mm}$; 3) the depth of indentation of grooved rolls in sheet $\Delta \mathrm{h}_{1}=0.25 \ldots 0.50$ mm (Fig. 3); 4) reduction per pass during sheet rolling with flat rolls $\varepsilon=50 \%$. Peripheral speeds of the top and bottom rolls in all calculation variants were set $\mathrm{V}=1.0$ $\mathrm{m} / \mathrm{sec}$.

In the course of simulation of cold rolling with flat and grooved rolls, the influence of the roll shape on strain distribution through $\mathrm{Al}$ sheet thickness was studied. a
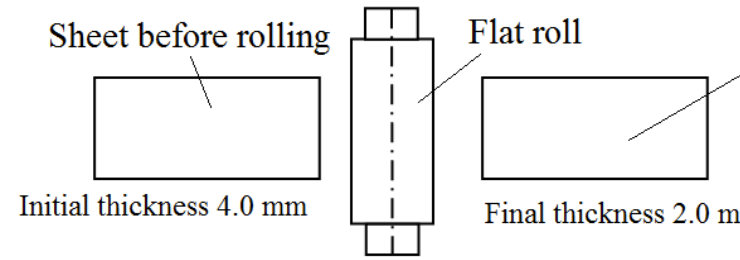

Final thickness $2.0 \mathrm{~mm}$
Sheet after single

pass reduction $50 \%$ $\mathrm{b}$

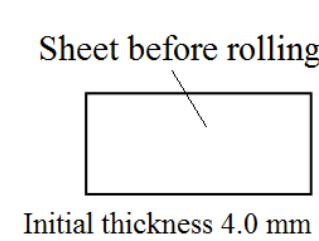

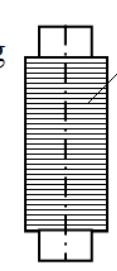

Groo

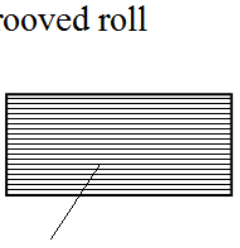

Sheet with grooves

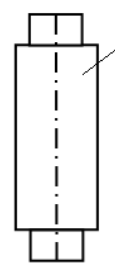

Flat roll

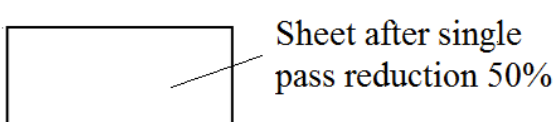

Final thickness $2.0 \mathrm{~mm}$
Sheet after single

pass reduction $50 \%$

Figure 1. The scheme of cold rolling with flat (a) and grooved (b) rolls (top view)

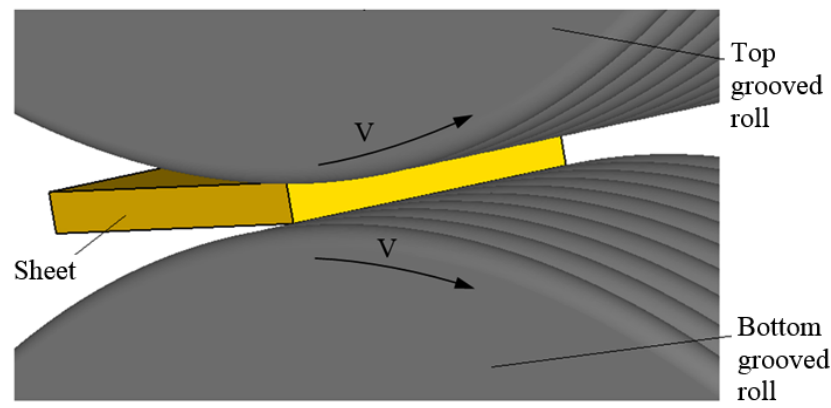

Figure 2. FE model of the cold sheet rolling with grooved rolls

For verification of the numeric modeling results, the experimental analysis was carried out. Experimental cold rolling with flat and grooved rolls was performed on a laboratory mill in which the working rolls had equal diameters of $200 \mathrm{~mm}$. No lubrication was introduced to the rolls. The surface profile of the Al sheets was measured with a contour measurement system MarSurf XC20. The microstructure of the samples after cold rolling was examined with an optical microscopy.

\section{Simulation results and discussion}

As the research showed, the surface layer is better treated in the case of cold sheet rolling with grooved

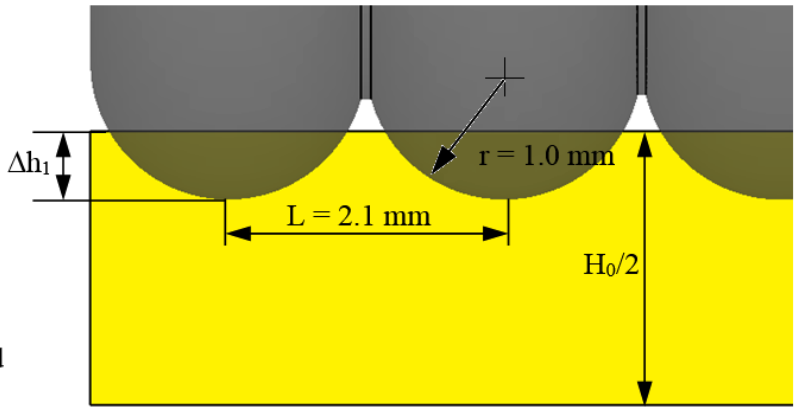

Figure 3. Dimensions of grooves on roll surface

rolls (Fig. 4-5). However, strain is distributed irregularly throughout the cross section of the sheet. Strain effective

is maximum $(\sim 1.5)$ on the top and bottom surfaces of the sheet. Strain $(\sim 0.9)$ is distributed regularly in case of cold rolling with flat rolls (Fig. 4). Comparison between experiment and FEM demonstrates its qualitative (Fig. 6) and quantitative (Fig.7) adequacy. By analyzing the results of simulation for different rolling processes, it can be inferred that the strain effective is much higher on the surface of the sheet (point P1) during cold rolling with grooved rolls (Fig. 8). It can be explained by additional transverse metal flow due to longitudinal grooves. Sheet metal rolled in grooved rolls has more refined grain size than sheet metal rolled in flat rolls 
only. That leads to getting higher mechanical properties of $\mathrm{Al}$ sheets.

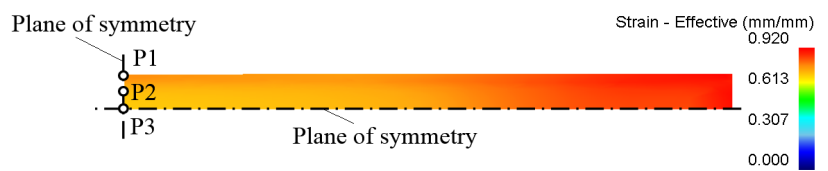

Figure 4. Strain effective field on the cross section of rolled sheet after cold rolling with only flat rolls
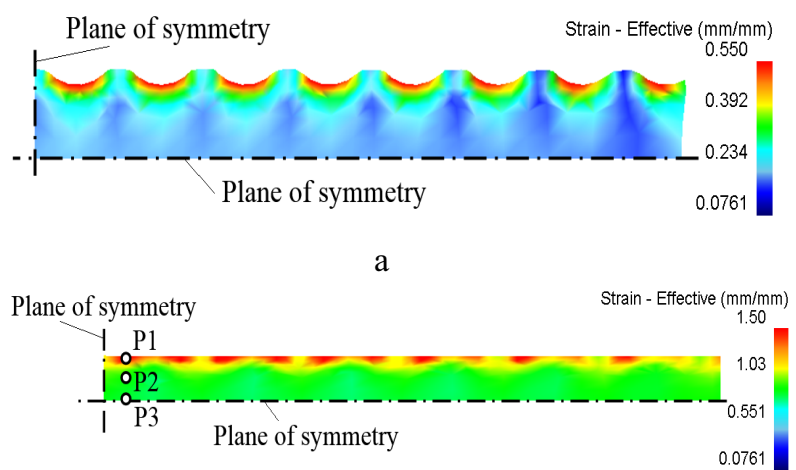

b

Figure 5. Strain effective field on the cross section of rolled sheet after cold rolling with grooved ( $\mathrm{h} 1=0.50 \mathrm{~mm}$ ) (a) and flat (b) rolls
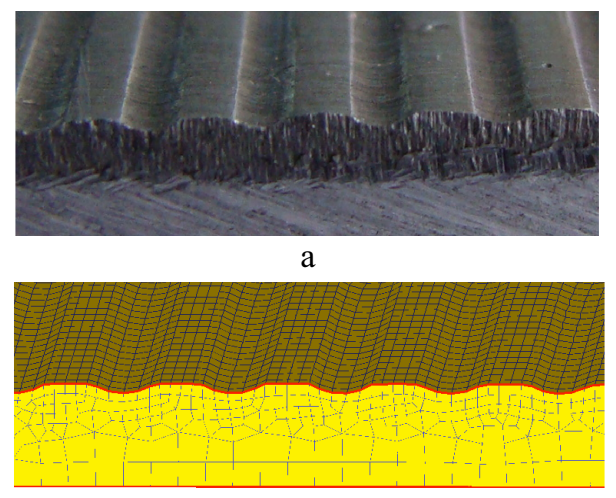

$\mathrm{b}$

Figure 6. Experimental (a) and calculated (b) sheet profile after cold rolling with grooved rolls $(\mathrm{Dh} 1=0.25 \mathrm{~mm})$

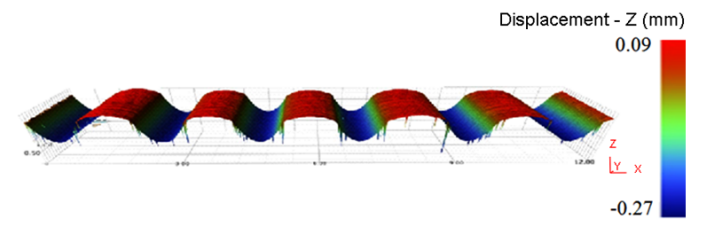

a

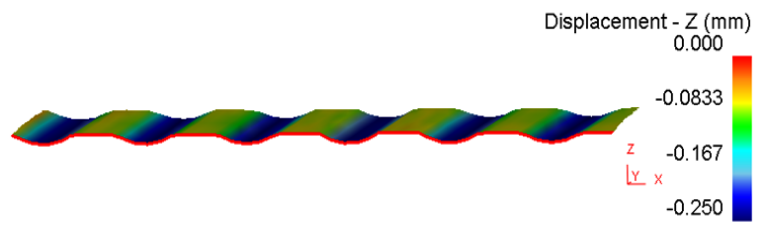

b

Figure 7. Measured (a) and calculated (b) z-displacement $(\mathrm{Dh} 1=0.25 \mathrm{~mm})$

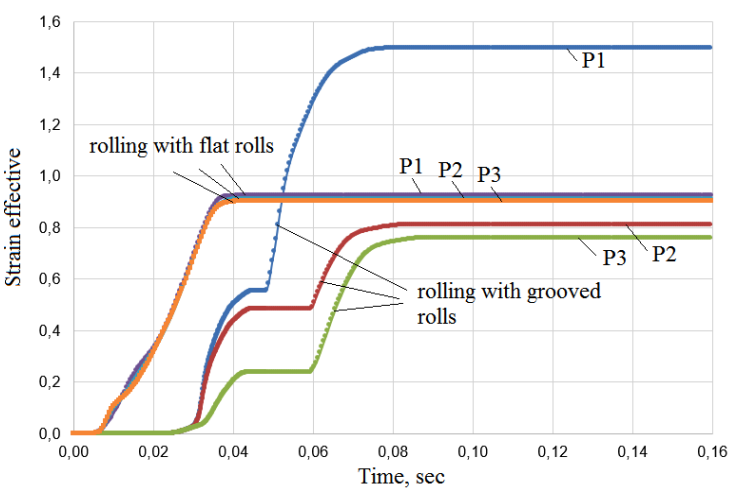

Figure 8. Strain effective distribution through sheet thickness (points P1-P3) during cold rolling with flat and grooved rolls $(\mathrm{Dh} 1=0.50 \mathrm{~mm})$

\section{Conclusions}

The numerical determination of strain distribution through Al sheet thickness during cold rolling with flat and grooved rolls was presented in this paper. Comparison between experiment and FEM demonstrates its qualitative and quantitative adequacy. The strain effective increases from 0.9 to 1.5 during cold rolling with grooved rolls, when depth of indentation of grooved rolls in sheet increases from 0.25 to $0.50 \mathrm{~mm}$. Increasing of strain can be explained by additional transverse metal flow due to longitudinal grooves. However, strain is distributed irregularly throughout the cross section of the sheet. FE model can be used to optimize the cold rolling process to improve microstructure and mechanical properties of aluminum sheets.

\section{Acknowledgements}

The study was supported by a grant of the Russian Science Foundation (project No15-19-10030)

\section{References}

1. V.I. Elagin, Paths of development of high-strength and heat-resistant structural aluminum alloys in the 21st century, Metal Science and Heat Treatment. 9 (2007) 3-11.

2. Laszlo S. Toth, Chengfan Gu, Ultrafine-grain metals by severe plastic deformation, Materials Characterization. 92 (2014) 1-14.

3. R.K Islamgaliev, N.F Yunusova, I.N Sabirov, A.V Sergueeva, R.Z Valiev, Deformation behavior of nanostructured aluminum alloy processed by severe plastic deformation, Materials Science and Engineering: A. 319-321 (2001) 877-881.

4. Jiang Jianhua, Ding Yi, Zuo Fangqing, Shan Aidang, Mechanical properties and microstructures of ultrafine-grained pure aluminum by asymmetric rolling, Scripta Materialia. 60 (2009) 905-908. 
5. A. Pesin, D. Pustovoytov, Influence of process parameters on distribution of shear strain through sheet thickness in asymmetric rolling, Key Engineering Materials. 622-623 (2014) 929-935.

6. K. Shimoyama, S. Yokoyama, S. Kaneko, F. Fujita, Effect of grooved roll profiles on microstructure evolutions of AZ31 sheets in Periodical Straining Rolling process, Materials Science and Engineering: A. 611 (2014) 58-68.

7. H. Utsunomiya, T. Ito, R. Matsumoto, Flattening of surface grooves in cold flat rolling, Procedia Engineering. 81 (2014) 155-160.

8. [8] K. Tanikawa, Y. Hosoya, A. Nishimoto, Influence of cold rolling with grooved rolls on the texture formation of steel sheets, Textures and Microstructures. 14-18 (1991) 1245-1250.

9. Sung-Hoon Cha, Jong-Bong Kim, Jong-Ho Kim, Hye-Jin Lee, Analysis of a Micro Pattern Forming on the Thin Sheet Metal for Electronic Device, NUMIFORM 2010: Proceedings of the 10th International Conference on Numerical Methods in Industrial Forming Processes. 1252 (2010) 198-205.

10. E. Niţu, M. Iordache, L. Marincei, I. Charpentier, G. Le Coz, G. Ferron, I. Ungureanu, FE-Modeling of Cold Rolling by In-Feed Method of Circular Grooves, Journal of Mechanical Engineering. 57 (2011) 667-673.

11. D.V. Shevchenko, D.Yu. Saraev, D.L. Nesterenko, A.I. Borovkov, FEM study of metal rolling in grooved rolls, Proceedings of the 8th European LS-DYNA Users Conference. (2011) http://www.dynalook.com/8th-european-ls-dyna-c onference/session-11/Session11_Paper6.pdf 